\title{
ESTIMATIVA DO IMPACTO DO COMÉRCIO BRASIL-CHINA SOBRE O TRABALHO POR NÍVEL DE QUALIFICAÇÃO
}

\author{
Willian Fabricio Arboleya Lopes ${ }^{1}$ \\ Umberto Antonio Sesso Filho ${ }^{2}$ \\ Emerson Guzzi Zuan Esteves ${ }^{3}$
}

Resumo: O objetivo da pesquisa foi estimar o efeito do comércio Brasil-China em geração de horas de trabalho por qualificação e identificar os setores com maiores impactos. Os resultados mostraram que no período 1995-2009 as relações entre os países modificaram-se com a tendência de o Brasil exportar produtos primários para a China e adquirir produtos com maior valor agregado e tecnologia. A consequência deste fenômeno foi que a balança comercial positiva do ano de 2009 em 4,7 bilhões de dólares para o Brasil apresentou saldo negativo de geração de trabalho em 520 milhões de horas, principalmente de média qualificação. Os setores do Brasil com maior geração de trabalho em 2009 por exportações para a China foram Agropecuária (1778 milhões de horas) e Extrativismo mineral (644 milhões de horas). Na China, temos os setores Produtos Elétricos e ópticos (1474 milhões de horas de trabalho geradas por exportações para o Brasil), Têxtil (561 milhões de horas) e Máquinas (249 milhões de horas).

Palavras-chave: Comércio. Exterior. Importação. Exportação. Qualificação.

\section{FOREIGN TRADE BRAZIL-CHINA IMPACT ESTIMATION OVER LABOR PER SKILL LEVEL}

\begin{abstract}
The objective of the study was to estimate the effects of generation of work hours by level of qualification considering the Brazil-China trade and to identify the sectors that suffered the greatest impact. The results showed that in the period 1995-2009 the relations between countries with the tendency of Brazil to export primary products to China and to acquire products with higher added value and technology. The consequence of this phenomenon is that the 2009 positive trade balance of US $\$ 4.7$ billion for Brazil resulted in a negative balance of work generation in 520 million hours, mainly of average qualification. The sectors of Brazil that exports to China generated more work in 2009 were Agropecuaria (1778 million hours) and Mineral Extraction (644 million hours). In China we have the Electric and optical products sectors (1474 million working hours generated by exports to Brazil), Textile (561 million hours) and Machines (249 million hours).
\end{abstract}

Keywords: Trade. Foreign. Import. Export. Qualification.

\section{ESTIMACIÓN DEL IMPACTO DEL COMERCIO BRASIL-CHINA SOBRE EL TRABAJO POR NIVEL DE CALIFICACIÓN}

Resumen: El objetivo de la investigación fue estimar el efecto del comercio BrasilChina en generación de horas de trabajo por calificación e identificar los sectores con mayores impactos. Los resultados mostraron que en el período 1995-2009 las

\footnotetext{
1 Escola Superior de Agricultura Luiz de Queiroz - Universidade de São Paulo (ESALQ-USP), Departamento de Economia, Administração e Sociologia, Piracicaba, Brasil, arboleya@usp.br, https://orcid.org/0000-0001-5023-4778

2 Universidade Estadual de Londrina, Departamento de Economia, Londrina, Brasil, umasesso@uel.br, https://orcid.org/0000-0003-4691-7343

3 Universidade Estadual de Londrina, Departamento de Economia, Londrina, Brasil, emerson.esteves@uel.br, https://orcid.org/0000-0003-0194-8998
} 
relaciones entre los países se modificaron con la tendencia de Brasil a exportar productos primarios a China y adquirir productos con mayor valor agregado y tecnología. La consecuencia de este fenómeno fue que la balanza comercial positiva del año 2009 en 4,7 mil millones de dólares para Brasil presentó un saldo negativo de generación de trabajo en 520 millones de horas, principalmente de media calificación. Los sectores de Brasil con mayor generación de trabajo en 2009 por exportaciones a China fueron Agropecuaria (1778 millones de horas) y extractivismo mineral (644 millones de horas). En China, tenemos los sectores Productos Eléctricos y Ópticos (1474 millones de horas de trabajo generadas por exportaciones a Brasil), Textil (561 millones de horas) y Máquinas (249 millones de horas).

Palabras clave: Comercio. Exterior. Importación. Exportación. Cualificación.

\section{Introdução}

A literatura econômica fundamenta que a política de comércio internacional estruturada aliada com uma atuação constante são fatores importantes para 0 desenvolvimento de um país. Caso contrário, a ausência do primeiro pode levar um país a cometer erros na abertura ou fechamento de sua economia. Uma atuação inconstante dificulta a obtenção de acordos consistentes, que possam trazer benefícios reais às relações comerciais. A abertura comercial tem sido debatida como fator de aumento de desigualdade social causada por diferenças salariais por níveis de qualificação e aumento do desemprego de pessoas com baixa qualificação.

As pautas de exportação dos países podem ser modificadas ao longo do tempo, inovações tecnológicas, mudança da qualificação do trabalhador e outros fatores podem influenciar as relações comerciais entre os países. Portanto, deve-se considerar que as vantagens comparativas são dinâmicas e podem ser transformadas levando os países a mudar seu comportamento no mercado internacional.

As exportações trazem ao país divisas e causam impacto nas cadeias produtivas em trabalho, renda, produção e outras variáveis impulsionando a economia interna. A ferramenta insumo-produto possibilita mensurar os impactos causados pelas exportações nos diversos setores da economia e suas cadeias produtivas.

O estudo busca estimar os efeitos de geração de horas de trabalho por nível de qualificação considerando o comércio Brasil-China e identificar os setores que sofreram maiores impactos. Para alcançar os objetivos propostos foi utilizada a ferramenta Insumo-Produto utilizando a matriz mundial dos anos 1995 e 2009 . Os níveis de qualificação estão divididos em baixa, média e alta. 
O texto é composto por cinco seções incluindo a introdução. Na segunda seção são resgatados os principais conceitos acerca do comércio internacional entre o Brasil e China. A terceira descreve a metodologia utilizada para especificação dos níveis de qualificação entre ambos países e o uso da ferramenta matriz insumoproduto. Na quarta, está a análise dos principais resultados. Por fim, as conclusões a partir dos objetivos propostos.

\section{Histórico recente do comércio internacional do Brasil e efeitos sobre o emprego}

Esta seção apresenta as referências acerca da importância das relações comerciais entre o Brasil e a China e a demanda por trabalho de alta qualificação por conta da abertura comercial. Para que os países desenvolvam relações comerciais, suas economias devem ser abertas (total ou parcialmente). POPKOVA e SUCHODOLOV (2017) classifica a abertura econômica em dois tipos, a voluntária e a compulsória. A primeira indica maior nível de desenvolvimento devido à expansão da oferta e demanda entre os países aumentando a concorrência interna, o que estimula a especialização e desenvolvimento de produtos mais competitivos e melhores. Já a segunda acontece por meio de acordos comerciais regulamentados entre países, os quais podem não ser tão rentáveis se um país não tivesse autonomia para negociar com os que melhor oferecem tal mercadoria, insumo, bem de capital, entre outros. A caracterização desta liberdade de comércio se dá pelas medidas protecionistas (tarifárias ou não) de cada país, onde o nível de maturidade econômica está de acordo com quão desenvolvido é seu comércio internacional. Nota-se que esse desenvolvimento tem como consequência o aperfeiçoamento técnico industrial e cai na contradição da industrialização orientada à exportação e substituição de importações.

A história da economia internacional mostra que a política de substituição de importações é comum nos países que estão em processo de desenvolvimento industrial. Como foi o caso dos EUA e dos países da Europa Ocidental na década de 1850, bem como ocorreu nos países latino-americanos, asiáticos e africanos. Essas políticas foram bastante criticadas nas décadas de 1970 e 1980, pois levaram os países em desenvolvimento a terem indústrias ineficientes. Isto trouxe a necessidade de mais medidas protecionistas (POPKOVA E SUCHODOLOV, 2017).

É importante destacar que as principais considerações da teoria neoclássica acerca do comércio exterior, conforme Bittencourt et al. (2008) são de que no longo 
prazo a abertura comercial traz ganhos econômicos ao país e aumento do bem-estar da população e no curto prazo existem ganhos de alguns agentes em detrimento de outros, os quais serão as indústrias mais dependentes de mão de obra menos qualificada. A situação é comum no caso de países como o Brasil, que possuem regiões com grandes disparidades econômicas regionais e distribuição de renda desigual.

Bittencourt et al. (2008) analisou os impactos regionais de curto e médio prazo na pobreza e na distribuição de renda após a abertura comercial por meio de um modelo de equilíbrio geral computável (EGC) considerando dois cenários: redução global de tarifas à Importação e em setores específicos. Constatou que os mais pobres sofrem impactos negativos e que há redução da desigualdade de renda inter-regional como um todo, apesar de não ser condição suficiente para mudança na estrutura de desigualdade regional.

A importância do comércio entre os países pode ser resumida como a capacidade de um país para exportar, o que depende do desenvolvimento de sua indústria nacional de forma eficiente. Isto o torna competitivo em todo o mercado internacional. Podendo vender suas mercadorias no exterior, ele recebe divisas que tornam a moeda nacional mais forte e aumenta o poder de compra. Assim, pode-se importar bens que não produz ou não tem eficiência, de tal forma que pode aumentar o bem-estar da população bem como aperfeiçoar sua própria indústria com bens de capital. Por fim, os resultados empíricos mostram que países que não possuem atividade de comércio internacional regular devem trabalhar em suas políticas para que tenham melhores perspectivas de crescimento e desenvolvimento (POPKOVA E SUCHODOLOV, 2017).

Ao final da década de 1980 e início de 1990, houve a abertura comercial brasileira que ocorreu de forma unilateral por meio de reduções tarifárias, diminuição das barreiras às importações e decréscimo da presença da política de substituição de importações. O impacto conforme De Paiva Abreu (2015) foi "abrangente e significativo" e podem ser apontadas algumas consequências como a penetração de importações nos setores de equipamentos de transporte e bens de capital, bens intermediários com pouca sofisticação e de consumo não duráveis. Outra consequência foi o aumento da produtividade do trabalho e de forma menos expressiva a produtividade de outros fatores. Acerca da distribuição de renda teve pouca influência. Porém, a valorização do trabalho qualificado aumentou no Brasil. Em relação às empresas, apesar da facilitação ao acesso de bens de capital e 
insumos, não houve impacto considerável à produtividade total dos fatores.

$\mathrm{Na}$ segunda metade da década de 1990, a abertura comercial brasileira sofreu uma reversão por conta do choque do balanço de pagamentos, crise mexicana e criação do Mercosul. Neste último, apesar do Brasil ter aumentado seu volume de exportações aos países membros e ser o principal representante, suas importações cresceram de forma mais lenta. Em complemento ao acima exposto, Puga (2005) analisou 23 setores brasileiros no período de 1993 a 2003 e afirmou que em 10 desses (produtos de minerais não-metálicos; móveis e diversos; indústria de alimentos e bebidas; agropecuária; outros transportes; veículos automotores; extrativa mineral; petróleo e álcool; material eletrônico e comunicações) houve crescimento nas exportações brasileiras ao mundo.

Pautasso (2010) aponta que a abertura comercial brasileira ocorreu sem devido planejamento ou contrapartidas, o que elevou as taxas de juros, apreciou o câmbio, restringiu o crédito e com baixos investimentos em logística dificultaram a política de exportações em detrimento às importações. O resultado no final da década foi a estagnação do comércio internacional brasileiro, causado por um fechamento aos mercados externos e abertura do mercado doméstico.

O início da década de 2000 foi marcado pelo crescimento da economia mundial e relações comerciais internacionais. Passin (2008), Siqueira (2006) e Giambiagi (2011) afirmam que a alta dos preços das commodities foi o principal fator responsável pelo aumento das exportações brasileiras no período de 2000 a 2005. Todavia, Puga (2006) leva todos os fatores citados em consideração, mas aponta como principal fator para o crescimento das exportações a rápida resposta dos produtores/exportadores frente ao aumento da demanda mundial e aumento de preços. Segundo Schmidt Filho (2011) o principal fator foi o aperfeiçoamento da abertura comercial ocorrida na década anterior, onde a política de comércio exterior brasileiro priorizou a ampliação e a diversificação dos mercados de exportação por meio da desoneração dos tributos relativos às exportações, nas importações ocorreram alguns incentivos pontuais. O resultado foi a expansão dos mercados atendidos pelo Brasil, como a China, a Rússia, Japão e alguns países africanos.

A mudança das relações exteriores do Brasil coincidiu com grandes transformações da política e dos negócios internacionais. Em 2009, a China tornouse o maior parceiro comercial do Brasil e o principal destino das exportações brasileiras (13,1\% do total). Em contrapartida, o Brasil representava apenas 1,3\% das exportações chinesas. Os EUA eram até aquele momento o principal parceiro 
comercial, porém devido à crise subprime as exportações americanas diminuíram enquanto as chinesas só aumentaram. Os desafios das exportações brasileiras permanecem pelo fato dos produtos se concentrarem principalmente em commodities agrícolas, que por sua vez são muito sensíveis às variações do mercado.

Apesar de serem países emergentes, Schmidt Filho (2011) afirma que a abertura comercial e desenvolvimento da política de comércio exterior chinês e brasileiro ocorreram de formas distintas. Enquanto o primeiro abriu sua economia em meados da década de 1980 utilizando-se do processo de catching up industrial, investimentos intrarregionais e modelo de desenvolvimento voltado às exportações. A abertura comercial brasileira ocorreu somente em meados de 1990 e a indústria nacional não aproveitou para ampliar sua competitividade de forma eficiente, o que a fez perder espaço dentro e fora do país. Além dessas discrepâncias acima expostas, Passin (2008) complementa que a China foi modificando sua pauta exportadora ao longo do tempo, passando de produtos com baixo valor agregado para produtos de alta tecnologia como por exemplo: eletrônicos e bens de capital. Quanto ao Brasil nota-se o efeito inverso, Schmidt Filho e Bittencourt (2010) afirma que existe baixa presença no mercado internacional de setores de alta tecnologia e uma alta concentração de exportação em setores estagnados como é o caso das commodities agrícolas. Pautasso (2010) aponta como opostas as políticas de abertura comercial adotadas pelo Brasil e China.

Lemoine (2017) descreve que após a crise subprime, a economia chinesa cresceu mais rápido que seu comércio internacional. Desde então, o principal movimentador do comércio chinês vem sendo sua demanda interna e não mais a demanda externa. Porém, isso não impediu o crescimento do comércio exterior chinês nos períodos de 2007 a 2015, o qual vem liderando desde 2013. Até mesmo as importações chinesas têm mostrado uma tendência de mudança - uma queda nas importações de produtos intermediários e semiacabados de seus parceiros asiáticos e um aumento na importação de produtos com alta qualidade e tecnologia da Europa. Em outras palavras, a China tem se tornado cada vez mais um país voltado ao comércio doméstico de produtos de alta tecnologia.

É importante observar que o crescimento chinês tem despertado grande preocupação aos países emergentes, já que pode dificultar sua inserção e/ou manutenção no mercado internacional. Segundo Carmo (2014), no caso brasileiro a disputa comercial com a China está mais acirrada, o Brasil até o momento não 
perdeu parcela significativa do mercado do Mercosul por conta da qualidade superior dos produtos brasileiros em detrimento aos chineses em alguns segmentos e da distinção de mercados atendidos. Em consonância, Pautasso (2010) e Passin (2008) atentam ao fato da primarização da pauta exportadora brasileira, que aumentou a participação de commodities agrícolas por conta do aumento dos preços. Isto pode representar um problema dada a volatilidade do mercado e dos preços. A proposta para a superação deste desafio é ampliar a pauta exportadora brasileira com produtos de alto valor agregado.

As afirmações anteriores podem ser justificadas por Wood (1997), que no estudo sobre a abertura comercial e diferença salarial por nível de qualificação indicou que a abertura comercial do Leste Asiático (nas décadas de 1960 e 1970) corroborou com a teoria de que a disparidade salarial entre trabalhadores com baixa e alta qualificação foi atenuada dada a abertura comercial dos países. Todavia, a abertura ocorrida na América Latina a partir da segunda metade da década de 80 aumentou a disparidade salarial entre pessoal com alta em relação e de baixa qualificação. O mesmo conclui que isso não ocorreu pelas diferenças regionais e sim pela época da abertura comercial de cada um. $O$ fenômeno foi causado por advento da tecnologia também exercer parcela significante nessa disparidade.

Wood (1995) critica a abertura comercial e argumenta que ela é a principal causa do prejuízo dos trabalhadores com baixa qualificação, tanto na redução de postos de trabalho quanto numa disparidade de salário cada vez mais acentuada. Em consonância com Wood (1997), num estudo acerca do comércio internacional, mudança de tecnologia e da demanda final na estrutura do emprego no Brasil, Maia (2003), concordando com Abreu (2007) afirma que o comércio internacional foi um dos fatores que impactaram negativamente a geração de postos de trabalho no Brasil, no período de 1985 até 1995. Todavia, a liberalização incentivou o aumento da demanda por trabalho qualificado, principalmente para as exportações.

Miller e Upadhyay (2010) num estudo mensurando efeitos da abertura econômica no capital humano, mostra que o estoque deste contribui positivamente para o aumento da produtividade do país em alguns casos, como por exemplo o efeito positivo em países com taxas de salários medianas. Quanto aos de baixos salários, o efeito se torna positivo à medida que aumenta o nível de abertura comercial. Em relação aos de níveis de salários mais elevados, o efeito se mostrou inverso.

Baseando-se na literatura apresentada pode-se afirmar que o comércio 
internacional é fator determinante às nações que desejam manter seu nível de crescimento. Contudo, deve-se observar que a abertura econômica pode trazer consequências negativas ao aspecto social agravando as diferenças salariais entre os trabalhadores de baixa, média e alta qualificação. Para que este problema seja minimizado torna-se importante que o país realize investimentos em qualificação do trabalhador (NEIVA, 2016).

\section{Metodologia}

O presente estudo consiste na estimativa da demanda por trabalho por nível de qualificação. A seguir é explicada a forma de obtenção dos dados secundários e do método de cálculo dos multiplicadores e geradores. Como proxy da demanda por trabalho, são consideradas as horas de trabalho de pessoas engajadas. Conforme o Instituto Brasileiro de Geografia Estatística (IBGE) pessoas engajadas (ocupadas) são aquelas que trabalham de forma remunerada ou não, ao menos uma hora semanal completa.

O Quadro 1 apresenta os critérios utilizados para o Brasil e à China. Para a separação dos níveis de qualificação, a metodologia de mapeamento dos indicadores de qualificação do World Input-Output Database (WIOD) foi utilizada como base. Que por sua vez se baseou no padrão da International Standard Classification of Education (ISCED) para classificar os níveis de qualificação no Brasil e o China Household Income Project (CHIP) para a China (TIMMER, 2012).

Quadro 1 - Especificação dos níveis de qualificação Brasil-China

\begin{tabular}{|c|c|c|}
\hline Qualificação & Brasil & China \\
\hline Baixa & $\begin{array}{l}\text { Elementar (primário); Ensino } \\
\text { fundamental ou do primeiro grau; } \\
\text { Educação de jovens e adultos ou } \\
\text { supletivo do ensino fundamental ou do } \\
\text { primeiro grau; alfabetização de jovens } \\
\text { e adultos; creche; classe de } \\
\text { alfabetização; maternal, jardim de } \\
\text { infância. }\end{array}$ & $\begin{array}{l}\text { Nunca escolarizados; Aulas para } \\
\text { superar analfabetismo; Elementar } \\
\text { (primário); Ensino Fundamental e } \\
\text { Médio incompleto. }\end{array}$ \\
\hline Média & $\begin{array}{l}\text { Médio primeiro ciclo; Médio Segundo } \\
\text { ciclo; ensino médio regular ou do } \\
\text { segundo grau; educação de jovens e } \\
\text { adultos ou supletivo de ensino médio } \\
\text { ou do Segundo grau. }\end{array}$ & $\begin{array}{l}\text { Ensino médio completo; cursos } \\
\text { técnicos profissionalizantes, } \\
\text { incluindo os do ensino } \\
\text { fundamental. }\end{array}$ \\
\hline Alta & $\begin{array}{l}\text { Ensino Superior (graduação); Mestrado } \\
\text { e/ou Doutorado. }\end{array}$ & $\begin{array}{l}\text { Ensino superior incompleto, } \\
\text { completo e pós-graduação. }\end{array}$ \\
\hline
\end{tabular}

Fonte: Elaborado pelos autores a partir das informações obtidas em WIOD (2017). 
A matriz insumo-produto utilizada no trabalho foi obtida do WIOD para os anos de 1995 e de 2009. Os valores informados são expressos em milhões de dólares americanos, a preços correntes dos respectivos anos. A ferramenta utilizada foi a Matriz Insumo-Produto desenvolvida por Leontief no final da década de 1930. Este método consiste na observação de dados econômicos de uma determinada região geográfica. A base fundamental é a análise do ciclo da cadeia produtiva como um todo (MILLE e BLAIR, 2009).

A equação de Leontief é representada da seguinte maneira:

$$
X=(I-A)^{-1} Y
$$

Onde:

$L$ é a matriz inversa de Leontief de dimensão (nxn);

$A$ é a matriz de coeficientes de dimensão ( $n \times n)$;

l é a matriz identidade da matriz A de dimensão (nxn).

O modelo foi complementado para que se pudesse estudar a interação entre as regiões e então surgiu o modelo inter-regional (ou "modelo Isard"), conforme Guilhoto (2011). Dessa maneira, este modelo foi aplicado neste trabalho por tratarse da análise do fluxo de bens e serviços entre duas regiões (países) e geração de trabalho qualificado dentro da matriz mundial com quarenta países e restante do mundo.

A análise de impacto foi necessária neste trabalho, pois é preciso captar o impacto da demanda final de cada país, no trabalho por nível de qualificação. Conforme Guilhoto (2011), por meio da Equação 1 e dada a variação na demanda final, ou seja, em $\Delta Y$ causaria uma variação na variável $\Delta \mathrm{X}$. Isso pode ser expresso por:

$$
\begin{gathered}
\Delta X=(I-A)^{-1} \Delta Y \\
\Delta V=\hat{v} \Delta X
\end{gathered}
$$

Sendo:

$\hat{v}$ é a matriz diagonal (nxn) da variável trabalho;

$\Delta V$ é um vetor ( $n \times 1)$ impacto sobre as variáveis (horas totais, horas por baixa, média e alta qualificação);

$\Delta X$ é um vetor ( $n \times 1)$ de impacto sobre o volume da produção; 
$\Delta Y$ é um vetor ( $n \times 1)$ da demanda final, para o presente trabalho as exportações

$\Delta Y$ e $\Delta X$ são vetores $(n x 1)$ que mostram respectivamente, a estratégia setorial e os impactos sobre o volume da produção, enquanto que $\Delta V$ é um vetor ( $n \times 1)$ que representa o impacto sobre qualquer uma das variáveis tratadas, para este estudo o total de horas de trabalho por qualificação. Tem-se também que $\hat{v}$ é uma matriz diagonal (nxn) em que os elementos da diagonal são, respectivamente, os coeficientes de trabalho (milhões de horas), que são obtidos dividindo-se para cada setor o valor utilizado destas variáveis na produção total pela produção total do setor correspondente, isto é:

$$
v_{i}=\frac{V_{i}}{X_{i}}
$$

Para se obter o impacto sobre o volume total da produção, e de cada uma das variáveis que estão sendo analisadas, soma-se todos os elementos dos vetores $\Delta X$ e $\Delta V$.

\section{Resultados e discussão}

A Tabela 1 apresenta os valores dos fluxos comerciais entre Brasil e China em 1995. Nota-se os baixos valores de bens e serviços trocados entre os países, com saldo comercial negativo para o Brasil de US\$208 milhões em valor corrente. Destacam-se os saldos positivos para o Brasil de (3) Alimentos, bebidas e tabaco e (2) Mineração e extrativismo. Os saldos negativos do comércio Brasil-China são maiores para (14) Produção de equipamentos elétricos e ópticos e (4) Tecidos e produtos têxteis. A pauta de exportação do Brasil era constituída principalmente de bens primários enquanto a China apresentava produtos com maior tecnologia, como os produtos elétricos e eletrônicos.

Observando a Tabela 2 que possui os resultados do impacto do comércio internacional sobre o trabalho podemos notar que, comparativamente, o Brasil gerou menos horas de trabalho em todos os níveis de qualificação. O Brasil gerou por exportações para a China 193,1 milhões de horas e a China 996,6 milhões de horas de trabalho por exportações para o Brasil. Em valores absolutos tem-se respectivamente: 155,4 milhões de horas de trabalho de baixa qualificação; 29,9 milhões de horas de trabalho em média e 8,4 milhões de horas de alta qualificação 
por exportações do Brasil para a China. Para a China, temos em valores absolutos para baixa, média e alta qualificação tem-se 685,7; 292 e 19,1 milhões de horas.

O saldo negativo do Brasil em 1995 foi de 806,5 milhões de horas de trabalho do impacto do comércio internacional com a China. Os setores em destaque em geração de trabalho no Brasil para atender a demanda chinesa são (3) Alimentos, bebidas e tabaco; (1) Agricultura, caça, silvicultura e pesca, (5) Produção de couro, artefatos de couro e confecção de sapatos; (12) Metais básicos e metais fabricados e (2) Mineração e extrativismo. Em relação à China, destacam-se na geração de trabalho por exportações para o Brasil os setores (4) Tecidos e produtos têxteis, (14) Produção de equipamentos elétricos e ópticos e (1) Agricultura, caça, silvicultura e pesca.

Em 1995, apesar do comércio Brasil-China ser menos importante que as relações comerciais com Estados Unidos e Europa, havia expectativa do aumento dos fluxos comerciais por motivo da China necessitar de bens de consumo intermediário e alimentos. Isto foi confirmado na década de 2000 , pois o aumento da taxa de crescimento da economia chinesa elevou o fluxo comercial entre os países até a China se tornar o principal destino das exportações brasileiras.

Tabela 1 - Comércio entre Brasil e China no ano de 1995, valores correntes em milhões de US\$.

\begin{tabular}{|c|c|c|c|c|}
\hline \multirow{2}{*}{ \# } & \multirow{2}{*}{ Setores } & Brasil & China & \multirow{2}{*}{ Saldo* } \\
\hline & & Exportações* $^{*}$ & Exportações* $^{*}$ & \\
\hline 1 & Agricultura, caça, silvicultura e pesca & 34 & 42 & -8 \\
\hline 2 & Mineração e extrativismo & 87 & 2 & 85 \\
\hline 3 & Alimentos, bebidas e tabaco & 293 & 8 & 286 \\
\hline 4 & Tecidos e produtos têxteis & 4 & 209 & -205 \\
\hline 5 & Produção de couro, artefatos de couro e confecção de sapatos & 50 & 63 & -13 \\
\hline 6 & Madeira, produtos de madeira e cortiça & 2 & 11 & -9 \\
\hline 7 & Polpa, papel, produtos impressos e publicação em papel. & 27 & 9 & 18 \\
\hline 8 & Carvão coque, petróleo refinado e combustível nuclear & 3 & 3 & 0 \\
\hline 9 & Produtos químicos & 30 & 30 & -1 \\
\hline 10 & Borracha e plásticos & 4 & 63 & -59 \\
\hline 11 & Outros minerais não metálicos & 0 & 18 & -17 \\
\hline 12 & Metais básicos e metais fabricados & 103 & 64 & 39 \\
\hline 13 & Produção de máquinas (sem classificadas específica) & 30 & 50 & -20 \\
\hline 14 & Produção de equipamentos elétricos e ópticos & 11 & 259 & -248 \\
\hline 15 & Produção de equipamentos de transporte & 26 & 41 & -15 \\
\hline 16 & Produção de produtos sem classificação especificada e reciclagem & 1 & 34 & -33 \\
\hline
\end{tabular}




\begin{tabular}{|c|c|c|c|c|}
\hline 17 & Fornecimento de eletricidade, gás e água & 0 & 6 & -6 \\
\hline 18 & Construção & 0 & 0 & 0 \\
\hline 19 & $\begin{array}{l}\text { Vendas, manutenção e reparo de veículos automotivos e varejo de } \\
\text { combustíveis }\end{array}$ & 0 & 0 & 0 \\
\hline 20 & $\begin{array}{l}\text { Comércio atacadista, exceto vendas e manutenção de veículos } \\
\text { automotivos e reparo de bens domésticos }\end{array}$ & 0 & 0 & 0 \\
\hline 21 & $\begin{array}{l}\text { Comércio varejista, exceto vendas e manutenção de veículos automotivos } \\
\text { e reparo de bens domésticos }\end{array}$ & 0 & 0 & 0 \\
\hline 22 & Hotéis e restaurantes & 0 & 0 & 0 \\
\hline 23 & Transporte terrestre & 0 & 3 & -2 \\
\hline 24 & Transporte aquaviário & 0 & 0 & 0 \\
\hline 25 & Transporte aéreo & 0 & 0 & 0 \\
\hline 26 & Outros tipos de serviço de transporte (incluindo agências de viagem) & 0 & 2 & -2 \\
\hline 27 & Serviços postais e telecomunicações & 0 & 0 & 0 \\
\hline 28 & Intermediação financeira & 0 & 0 & 0 \\
\hline 29 & Aluguel de imóveis & 0 & 0 & 0 \\
\hline 30 & Aluguel de máquinas e equipamentos e outros negócios & 1 & 0 & 1 \\
\hline 31 & Administração pública, defesa nacional e seguro social & 0 & 0 & 0 \\
\hline 32 & Educação & 0 & 0 & 0 \\
\hline 33 & Saúde e trabalho social & 0 & 0 & 0 \\
\hline 34 & Outros serviços comunitários, sociais e pessoais & 1 & 0 & 1 \\
\hline & 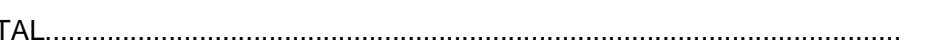 & 710 & 917 & -208 \\
\hline
\end{tabular}

* Milhões de dólares a preços correntes de 1995.

Fonte: Elaborado pelos autores com base em WIOD (2017).

Tabela 2 - Geração de horas trabalhadas por qualificação no comércio Brasil - China em 1995, valores em milhões de horas anuais.

\begin{tabular}{|c|c|c|c|c|c|c|c|c|c|}
\hline \multirow{3}{*}{ \# } & \multirow{3}{*}{ Setores } & \multicolumn{8}{|c|}{ Geração de horas de trabalho do fluxo comercial } \\
\hline & & \multicolumn{4}{|c|}{ Brasil } & \multicolumn{4}{|c|}{ China } \\
\hline & & Baixa & Média & Alta & Total & Baixa & Média & Alta & Total \\
\hline 1 & Agricultura, caça, silvicultura e pesca & 22,6 & 1,5 & 0,3 & 24,4 & 109,0 & 7,6 & 0,4 & 116,9 \\
\hline 2 & Mineração e extrativismo & 7,6 & 2,9 & 1,1 & 11,5 & 0,9 & 0,6 & 0,0 & 1,5 \\
\hline 3 & Alimentos, bebidas e tabaco & 93,6 & 13,4 & 3,3 & 110,2 & 11,2 & 1,9 & 0,1 & 13,2 \\
\hline 4 & Tecidos e produtos têxteis & 0,9 & 0,3 & 0,1 & 1,2 & 192,8 & 65,2 & 3,6 & 261,6 \\
\hline 5 & $\begin{array}{l}\text { Produção de couro, artefatos de couro e confecção de } \\
\text { sapatos }\end{array}$ & 10,1 & 3,3 & 0,8 & 14,3 & 58,2 & 17,6 & 1,1 & 76,9 \\
\hline 6 & Madeira, produtos de madeira e cortiça & 0,5 & 0,1 & 0,0 & 0,7 & 10,8 & 3,5 & 0,2 & 14,5 \\
\hline 7 & Polpa, papel, produtos impressos e publicação em papel. & 3,2 & 1,1 & 0,4 & 4,6 & 6,1 & 3,0 & 0,2 & 9,4 \\
\hline 8 & Carvão coque, petróleo refinado e combustível nuclear & 0,3 & 0,1 & 0,0 & 0,4 & 1,2 & 0,9 & 0,1 & 2,1 \\
\hline 9 & Produtos químicos & 2,4 & 1,0 & 0,3 & 3,7 & 16,4 & 9,7 & 0,7 & 26,8 \\
\hline 10 & Borracha e plásticos & 0,4 & 0,2 & 0,1 & 0,6 & 40,7 & 19,6 & 1,2 & 61,5 \\
\hline 11 & Outros minerais não metálicos & 0,0 & 0,0 & 0,0 & 0,1 & 10,8 & 6,0 & 0,3 & 17,1 \\
\hline 12 & Metais básicos e metais fabricados & 8,0 & 3,4 & 1,2 & 12,6 & 26,8 & 20,2 & 1,4 & 48,3 \\
\hline
\end{tabular}


13 Produção de máquinas (sem classificadas específica)

14 Produção de equipamentos elétricos e ópticos

15 Produção de equipamentos de transporte

16 Produção de produtos sem classificação especificada e reciclagem

17 Fornecimento de eletricidade, gás e água

18 Construção

19 Vendas, manutenção e reparo de veículos automotivos e varejo de combustíveis

20 Comércio atacadista, exceto vendas e manutenção de veículos automotivos e reparo de bens domésticos

21 Comércio varejista, exceto vendas e manutenção de veículos automotivos e reparo de bens domésticos

22 Hotéis e restaurantes

23 Transporte terrestre

24 Transporte aquaviário

25 Transporte aéreo

26

Outros tipos de serviço de transporte (incluindo agências de viagem)

27 Serviços postais e telecomunicações

28 Intermediação financeira

29 Aluguel de imóveis

30 Aluguel de máquinas e equipamentos e outros negócios

31 Administração pública, defesa nacional e seguro social

32 Educação

33 Saúde e trabalho social

34 Outros serviços comunitários, sociais e pessoais

Totais

\begin{tabular}{|c|c|c|c|c|c|c|c|}
\hline 2,4 & 1,0 & 0,3 & 3,8 & 23,6 & 18,0 & 1,3 & 42,9 \\
\hline 0,8 & 0,4 & 0,1 & 1,4 & 101,9 & 78,7 & 6,3 & 186,8 \\
\hline 1,9 & 0,9 & 0,3 & 3,1 & 17,6 & 14,4 & 1,1 & 33,0 \\
\hline 0,1 & 0,1 & 0,0 & 0,2 & 53,4 & 21,0 & 0,9 & 75,2 \\
\hline 0,0 & 0,0 & 0,0 & 0,0 & 1,9 & 1,9 & 0,2 & 4,0 \\
\hline 0,0 & 0,0 & 0,0 & 0,0 & 0,0 & 0,0 & 0,0 & 0,0 \\
\hline 0,0 & 0,0 & 0,0 & 0,0 & 0,0 & 0,0 & 0,0 & 0,0 \\
\hline 0,0 & 0,0 & 0,0 & 0,0 & 0,0 & 0,0 & 0,0 & 0,0 \\
\hline 0,0 & 0,0 & 0,0 & 0,0 & 0,0 & 0,0 & 0,0 & 0,0 \\
\hline 0,0 & 0,0 & 0,0 & 0,0 & 0,0 & 0,0 & 0,0 & 0,0 \\
\hline 0,1 & 0,0 & 0,0 & 0,1 & 1,3 & 1,2 & 0,1 & 2,6 \\
\hline 0,0 & 0,0 & 0,0 & 0,0 & 0,0 & 0,0 & 0,0 & 0,1 \\
\hline 0,0 & 0,0 & 0,0 & 0,0 & 0,0 & 0,0 & 0,0 & 0,1 \\
\hline 0,0 & 0,0 & 0,0 & 0,0 & 1,0 & 0,9 & 0,1 & 2,1 \\
\hline 0,0 & 0,0 & 0,0 & 0,0 & 0,0 & 0,0 & 0,0 & 0,0 \\
\hline 0,0 & 0,0 & 0,0 & 0,0 & 0,0 & 0,0 & 0,0 & 0,0 \\
\hline 0,0 & 0,0 & 0,0 & 0,0 & 0,0 & 0,0 & 0,0 & 0,0 \\
\hline 0,1 & 0,1 & 0,1 & 0,2 & 0,0 & 0,0 & 0,0 & 0,0 \\
\hline 0,0 & 0,0 & 0,0 & 0,0 & 0,0 & 0,0 & 0,0 & 0,0 \\
\hline 0,0 & 0,0 & 0,0 & 0,0 & 0,0 & 0,0 & 0,0 & 0,0 \\
\hline 0,0 & 0,0 & 0,0 & 0,0 & 0,0 & 0,0 & 0,0 & 0,0 \\
\hline 0,2 & 0,1 & 0,0 & 0,0 & 0,0 & 0,0 & 0,0 & 0,0 \\
\hline 55,2 & 29,9 & 8,4 & 193,1 & 685,6 & 291,9 & 19,3 & 996,6 \\
\hline
\end{tabular}

Fonte: Elaborado pelos autores.

A Tabela 3 possui os dados do comércio internacional Brasil-China no ano de 2009. A balança comercial do Brasil se mostrou positiva em 4,7 bilhões de dólares (em valores correntes de 2009). Portanto, o saldo comercial foi revertido comparado a 1995 (déficit de aproximadamente 208 milhões de dólares). Os maiores saldos positivos para o Brasil foram obtidos para os setores (2) Mineração e extrativismo, (1) Agricultura, caça, silvicultura e pesca, (12) Metais básicos. Os saldos comerciais negativos foram (14) Produção de equipamentos elétricos e ópticos, (4) Tecidos e produtos têxteis, (13) Produção de máquinas e (9) Produtos químicos. O Brasil manteve sua pauta de exportações de produtos primários enquanto a China diversificou e aumentou o comércio de produtos com maior valor agregado e tecnologia.

A Tabela 4 mostra os resultados da pesquisa para a mensuração do efeito do 
comércio internacional sobre 0 trabalho que em valores absolutos tem-se respectivamente: 1.913,4; 868,9 e 210,1 milhões de horas de trabalho geradas por exportações do Brasil para a China considerando baixa, média e alta qualificação. A China gerou por exportações para o Brasil, em valores absolutos, respectivamente 1.983,8; 1415,7 e 238,4 milhões de horas de trabalho em baixa, média e alta qualificação do trabalho. Portanto, a China expandiu a geração de trabalho de média qualificação comparativamente a 1995. Apesar da balança comercial positiva para o Brasil, o saldo de horas de trabalho gerado pelo comércio internacional beneficia a China em aproximadamente 520 milhões de horas de trabalho, principalmente de média qualificação. A geração de trabalho no Brasil para atender a demanda chinesa era maior dos setores (1) Agricultura, caça, silvicultura e pesca e (2) Mineração e extrativismo. Em relação à China, destacam-se os setores (14) Produção de equipamentos elétricos e ópticos, (4) Tecidos e produtos têxteis, (9) Produtos químicos e (13) Produção de máquinas.

Os resultados mostram a tendência do comércio em que o Brasil intensificou a aquisição de produtos com maior valor agregado e tecnologia e exportação de produtos primários. Além disso, ocorreu saldo comercial positivo e saldo negativo de geração de trabalho em 2009 para o Brasil. A geração de trabalho da China por exportações para o Brasil foi no ano de 1995 cerca de 997 milhões de horas e as proporções aproximadas de $69 \%$ de baixa qualificação, $29 \%$ de média e $2 \%$ de alta. Em 2009 o valor total mudou para 3511 milhões de horas com a participação de $57 \%$ de baixa, $40 \%$ de média e $3 \%$ de alta qualificação. Notadamente, houve esforço da China na qualificação do trabalhador. O Brasil seguiu esta tendência pois em 1995 as exportações para a China geraram 193 milhões de horas de trabalho com $80 \%$ de baixa, 16\% de média e 4\% de alta qualificação. Em 2009 foram 2992 milhões de horas de trabalho, $64 \%$ de baixa, $29 \%$ de média e $7 \%$ de alta qualificação. Ambos países diminuíram a participação do trabalho de baixa qualificação e aumentaram a participação do trabalho de média e alta qualificação, porém destaca-se que produtos com maior valor adicionado e tecnologia possuem cadeias produtivas que beneficiam a geração de trabalho de maior qualificação como foi o caso da economia chinesa.

Tabela 3 - Comércio entre Brasil e China no ano de 2009, valores correntes em milhões de US\$.

\begin{tabular}{llccc}
\hline \multirow{2}{*}{ \# } & Setores & Brasil & China & Saldo* $^{*}$ \\
\cline { 3 - 5 } & & Exportações $^{*}$ & Exportações $^{\star}$ & \\
\hline 1 & Agricultura, caça, silvicultura e pesca & 6392 & 79 & 6312
\end{tabular}




\begin{tabular}{|c|c|c|c|c|}
\hline 2 & Mineração e extrativismo & 9687 & 23 & 9663 \\
\hline 3 & Alimentos, bebidas e tabaco & 461 & 134 & 327 \\
\hline 4 & Tecidos e produtos têxteis & 26 & 1575 & -1549 \\
\hline 5 & Produção de couro, artefatos de couro e confecção de sapatos & 476 & 320 & 157 \\
\hline 6 & Madeira, produtos de madeira e cortiça & 56 & 22 & 34 \\
\hline 7 & Polpa, papel, produtos impressos e publicação em papel. & 858 & 46 & 812 \\
\hline 8 & Carvão coque, petróleo refinado e combustível nuclear & 14 & 72 & -57 \\
\hline 9 & Produtos químicos & 506 & 1709 & -1203 \\
\hline 10 & Borracha e plásticos & 28 & 452 & -424 \\
\hline 11 & Outros minerais não metálicos & 7 & 166 & -159 \\
\hline 12 & Metais básicos e metais fabricados & 1973 & 752 & 1221 \\
\hline 13 & Produção de máquinas (sem classificadas específica) & 151 & 1382 & -1231 \\
\hline 14 & Produção de equipamentos elétricos e ópticos & 188 & 8833 & -8645 \\
\hline 15 & Produção de equipamentos de transporte & 530 & 516 & 15 \\
\hline 16 & Produção de produtos sem classificação especificada e reciclagem & 6 & 217 & -211 \\
\hline 17 & Fornecimento de eletricidade, gás e água & 5 & 11 & -6 \\
\hline 18 & Construção & 0 & 0 & 0 \\
\hline 19 & $\begin{array}{l}\text { Vendas, manutenção e reparo de veículos automotivos e varejo de } \\
\text { combustíveis }\end{array}$ & 0 & 0 & 0 \\
\hline 20 & $\begin{array}{l}\text { Comércio atacadista, exceto vendas e manutenção de veículos } \\
\text { automotivos e reparo de bens domésticos }\end{array}$ & 0 & 33 & -33 \\
\hline 21 & $\begin{array}{l}\text { Comércio varejista, exceto vendas e manutenção de veículos } \\
\text { automotivos e reparo de bens domésticos }\end{array}$ & 1 & 386 & -385 \\
\hline 22 & Hotéis e restaurantes & 0 & 0 & 0 \\
\hline 23 & Transporte terrestre & 19 & 35 & -16 \\
\hline 24 & Transporte aquaviário & 1 & 5 & -4 \\
\hline 25 & Transporte aéreo & 2 & 2 & 0 \\
\hline 26 & Outros tipos de serviço de transporte (incluindo agências de viagem) & 9 & 4 & 5 \\
\hline 27 & Serviços postais e telecomunicações & 15 & 0 & 15 \\
\hline 28 & Intermediação financeira & 0 & 0 & 0 \\
\hline 29 & Aluguel de imóveis & 0 & 0 & 0 \\
\hline 30 & Aluguel de máquinas e equipamentos e outros negócios & 38 & 0 & 38 \\
\hline 31 & Administração pública, defesa nacional e seguro social & 4 & 0 & 4 \\
\hline 32 & Educação & 0 & 0 & 0 \\
\hline 33 & Saúde e trabalho social & 0 & 0 & 0 \\
\hline \multirow[t]{2}{*}{34} & Outros serviços comunitários, sociais e pessoais & 23 & 0 & 23 \\
\hline & Totais & 21476 & 16774 & 4702 \\
\hline
\end{tabular}

* Milhões de dólares a preços correntes de 2009.

Fonte: Elaborado pelos autores com base em WIOD (2018).

Tabela 4 - Geração de horas trabalhadas por qualificação no comércio Brasil - China em 2009, valores em milhões de horas anuais. 


\begin{tabular}{|c|c|c|c|c|c|c|c|c|c|}
\hline \multirow{3}{*}{$\#$} & \multirow{3}{*}{ Setores } & \multicolumn{8}{|c|}{ Geração de horas de trabalho do fluxo comercial } \\
\hline & & \multicolumn{4}{|c|}{ Brasil } & \multicolumn{4}{|c|}{ China } \\
\hline & & Baixa & Média & Alta & Total & Baixa & Média & Alta & Total \\
\hline 1 & Agricultura, caça, silvicultura e pesca & 1383,6 & 343,6 & 51,3 & 1778,4 & 51,0 & 4,8 & 0,4 & 56,2 \\
\hline 2 & Mineração e extrativismo & 268,7 & 279,8 & 95,4 & 643,9 & 1,9 & 1,6 & 0,2 & 3,7 \\
\hline 3 & Alimentos, bebidas e tabaco & 51,7 & 25,4 & 5,0 & 82,2 & 46,1 & 9,6 & 1,1 & 56,8 \\
\hline 4 & Tecidos e produtos têxteis & 3,3 & 2,9 & 0,5 & 6,8 & 406,9 & 139,5 & 14,9 & 561,3 \\
\hline 5 & $\begin{array}{l}\text { Produção de couro, artefatos de couro e confecção de } \\
\text { sapatos }\end{array}$ & 44,7 & 41,4 & 7,4 & 93,5 & 100,0 & 30,3 & 3,1 & 133,4 \\
\hline 6 & Madeira, produtos de madeira e cortiça & 5,1 & 4,7 & 1,2 & 11,0 & 6,2 & 2,2 & 0,2 & 8,6 \\
\hline 7 & $\begin{array}{l}\text { Polpa, papel, produtos impressos e publicação em } \\
\text { papel. }\end{array}$ & 40,3 & 35,4 & 9,6 & 85,3 & 8,8 & 5,0 & 0,6 & 14,4 \\
\hline 8 & Carvão coque, petróleo refinado e combustível nuclear & 0,5 & 0,4 & 0,1 & 0,9 & 3,8 & 3,4 & 0,6 & 7,7 \\
\hline 9 & Produtos químicos & 16,2 & 17,0 & 4,9 & 38,1 & 185,9 & 119,1 & 20,7 & 325,7 \\
\hline 10 & Borracha e plásticos & 1,1 & 1,2 & 0,3 & 2,6 & 66,6 & 39,1 & 5,4 & 111,1 \\
\hline 11 & Outros minerais não metálicos & 0,3 & 0,4 & 0,1 & 0,8 & 18,6 & 12,2 & 1,8 & 32,6 \\
\hline 12 & Metais básicos e metais fabricados & 61,4 & 74,1 & 21,3 & 156,9 & 55,4 & 45,7 & 7,9 & 109,0 \\
\hline 13 & Produção de máquinas (sem classificadas específica) & 5,1 & 6,1 & 1,8 & 13,0 & 124,1 & 106,3 & 18,2 & 248,6 \\
\hline 14 & Produção de equipamentos elétricos e ópticos & 6,2 & 7,7 & 2,2 & 16,1 & 719,2 & 631,6 & 122,8 & 1473,6 \\
\hline 15 & Produção de equipamentos de transporte & 16,8 & 20,4 & 5,9 & 43,1 & 43,5 & 38,1 & 6,7 & 88,4 \\
\hline 16 & $\begin{array}{l}\text { Produção de produtos sem classificação especificada } \\
\text { e reciclagem }\end{array}$ & 0,4 & 0,5 & 0,1 & 1,0 & 58,7 & 24,8 & 2,4 & 85,9 \\
\hline 17 & Fornecimento de eletricidade, gás e água & 0,1 & 0,1 & 0,0 & 0,2 & 0,6 & 0,7 & 0,2 & 1,5 \\
\hline 18 & Construção & 0,0 & 0,0 & 0,0 & 0,0 & 0,0 & 0,0 & 0,0 & 0,0 \\
\hline 19 & $\begin{array}{l}\text { Vendas, manutenção e reparo de veículos } \\
\text { automotivos e varejo de combustíveis }\end{array}$ & 0,0 & 0,0 & 0,0 & 0,0 & 0,0 & 0,0 & 0,0 & 0,0 \\
\hline 20 & $\begin{array}{l}\text { Comércio atacadista, exceto vendas e manutenção de } \\
\text { veículos automotivos e reparo de bens domésticos }\end{array}$ & 0,0 & 0,0 & 0,0 & 0,0 & 1,9 & 2,3 & 0,6 & 25,8 \\
\hline 21 & $\begin{array}{l}\text { Comércio varejista, exceto vendas e manutenção de } \\
\text { veículos automotivos e reparo de bens domésticos }\end{array}$ & 0,1 & 0,1 & 0,0 & 0,1 & 78,9 & 193,8 & 29,9 & 159,8 \\
\hline 22 & Hotéis e restaurantes & 0,0 & 0,0 & 0,0 & 0,0 & 0,0 & 0,0 & 0,0 & 0,0 \\
\hline 23 & Transporte terrestre & 1,1 & 1,2 & 0,3 & 2,6 & 4,4 & 4,7 & 0,6 & 4,9 \\
\hline 24 & Transporte aquaviário & 0,0 & 0,0 & 0,0 & 0,1 & 0,4 & 0,3 & 0,1 & 1,1 \\
\hline 25 & Transporte aéreo & 0,1 & 0,1 & 0,0 & 0,1 & 0,2 & 0,2 & 0,1 & 0,4 \\
\hline 26 & $\begin{array}{l}\text { Outros tipos de serviço de transporte (incluindo } \\
\text { agências de viagem) }\end{array}$ & 0,4 & 0,4 & 0,1 & 0,9 & 0,6 & 0,4 & 0,1 & 0,6 \\
\hline 27 & Serviços postais e telecomunicações & 0,5 & 0,5 & 0,2 & 1,2 & 0,0 & 0,0 & 0,0 & 0,0 \\
\hline 28 & Intermediação financeira & 0,0 & 0,0 & 0,0 & 0,0 & 0,0 & 0,0 & 0,0 & 0,0 \\
\hline 29 & Aluguel de imóveis & 0,0 & 0,0 & 0,0 & 0,0 & 0,0 & 0,0 & 0,0 & 0,0 \\
\hline 30 & $\begin{array}{l}\text { Aluguel de máquinas e equipamentos e outros } \\
\text { negócios }\end{array}$ & 1,8 & 2,6 & 1,6 & 6,0 & 0,0 & 0,0 & 0,0 & 0,0 \\
\hline 31 & Administração pública, defesa nacional e seguro social & 0,1 & 0,2 & 0,1 & 0,4 & 0,0 & 0,0 & 0,0 & 0,0 \\
\hline 32 & Educação & 0,0 & 0,0 & 0,0 & 0,0 & 0,0 & 0,0 & 0,0 & 0,0 \\
\hline 33 & Saúde e trabalho social & 0,0 & 0,0 & 0,0 & 0,0 & 0,0 & 0,0 & 0,0 & 0,0 \\
\hline
\end{tabular}




\begin{tabular}{cccc|cccc}
4,0 & 2,7 & 0,5 & 7,2 & 0,0 & 0,0 & 0,0 & 0,0 \\
1913,6 & 868,9 & 209,9 & 2992,4 & 1983,7 & 1415,7 & 238,6 & 3511,1
\end{tabular}

Fonte: Elaborado pelos autores.

\section{Considerações finais}

A ferramenta insumo-produto se mostrou adequada para mensurar o efeito do comércio entre países sobre o trabalho por qualificação. O período 1995-2009 mostra a modificação das relações Brasil-China com a tendência de o Brasil exportar produtos primários para a China e adquirir produtos com maior valor agregado e tecnologia. A consequência deste fenômeno é que a balança comercial positiva do ano de 2009 em 4,7 bilhões de dólares para o Brasil mostrou como resultado um balanço de geração de trabalho negativo em 520 milhões de horas de trabalho, principalmente de média qualificação.

Os setores beneficiados no Brasil nas relações comerciais com a China são principalmente Agropecuária e Extrativismo mineral. Na China temos os setores Produtos Elétricos e ópticos, Têxtil e Máquinas. A diversificação da pauta de exportação da China no período 1995-2009 mostra o dinamismo desta economia e sua estratégia de atuação de adicionar valor e tecnologia aos produtos comercializados, isto levou ao aumento da geração de trabalho de maior qualificação. O Brasil mostrou aumento da participação do trabalho de média e alta qualificação. Porém, a exportação de produtos primários não beneficia a geração de trabalho qualificado. Neste contexto, o Brasil deveria aumentar o nível de industrialização e diferenciação dos produtos para melhorar o saldo de trabalho em suas relações comerciais. Além disso, investimentos em qualificação profissional e o contínuo aumento da escolaridade média do trabalhador são aspectos importantes para o país.

Novas pesquisas podem ser realizadas explorando detalhes das cadeias produtivas globais e identificando oportunidades para atuação do Brasil. Assim como estimar o efeito do comércio internacional sobre a geração de renda, emprego e qualificação para diferentes períodos.

\section{REFERÊNCIAS}

ABREU, Marcelo de Paiva (org). A Ordem do Progresso: Dois Séculos de Política Econômica no Brasil. Brasil: Elsevier, 2015. 
ABREU, Marcelo de Paiva. Comércio exterior: interesses do Brasil. Brasil: Elsevier, 2007.

BITTENCOURT, Mauricio Vaz Lobo; LARSON, Donald W.; KRAYBILL, David L. A Liberalização comercial e os impactos regionais sobre a pobreza e a distribuição de renda no Brasil. Brasil, 2008.

CARMO, Alex Sander Souza do; BITTENCOURT, Maurício Vaz Lobo; RAIHER, Augusta Pelinski. A competitividade das exportações do Brasil e da China para o Mercosul: evidências para o período 1995-2009. Brasil: Nova Economia, v. 24, n. 3, p. 587-607, 2014.

SIQUEIRA, Tagore Villarim. Comércio internacional: oportunidades para o desenvolvimento regional. Brasil, 2006.

M Fujita, PR Krugman, AJ Venables. The spatial economy: cities, regions and international trade. Cambridge, MA: MIT press, 1999.

GIAMBIAGI, Fabio; VILLELA, André Arruda. Economia brasileira contemporânea. Brasil: Elsevier, 2011.

GUILHOTO, Joaquim José Martins. Análise de insumo-produto: teoria e fundamentos. Brasil, 2011.

IBGE. Pesquisa Nacional por Amostra de Domicílios Contínua: Conceitos e Definições. Disponível em: < http://www.ibge.gov.br/home/estatistica/indicadores/trabalhoerendimento/pnad continua/pri meiros resultados/analise01.shtm >. Acesso em: 20/05/2017.

LEMOINE, Francoise; UNAL, Deniz. China's Foreign Trade: A "New Normal". China \& World Economy, v. 25, n. 2, p. 1-21, 2017.

MAIA, Katy. Os impactos do comércio internacional, da mudança tecnológica e da demanda final na estrutura de emprego no Brasil, 1985-1995. Economia aplicada, v. 7, n. 2, p. 327357, 2003.

MILLER, Ronald E.; BLAIR, Peter D. Input-output analysis: foundations and extensions. Cambridge University Press, 2009.

MILLER, Stephen M.; UPADHYAY, Mukti P. The effects of openness, trade orientation, and human capital on total factor productivity. Journal of development economics, v. $63, n$. 2 , p. 399-423, 2000.

NEIVA, Leonardo José Feitosa; HALIK, Aline Roberta; FALCÃO, Maurin Almeida. Desenvolvimento: Uma análise a partir do Comércio Internacional e do Capital Humano. Teresina: FSA. 2016.

PASSIN, Jorge Antonio Bozoti. Impactos da abertura chinesa sobre o comércio internacional (1998-2006). Revista do BNDES, Rio de Janeiro, v. 14, n. 29, 2008.

PAUTASSO, Diego. O lugar da China no comércio exterior brasileiro. Meridiano 47, v. 11, n. 114, p. 28, 2010.

POPKOVA E SUCHODOLOV, Elena G.; SUKHODOLOV, Yakov A. Foreign Trade as a Factor of Economic Growth: Russian-Chinese Foreign Trade Cooperation. Switzerland: Springer, 2017.

PUGA, Fernando. A inserção do Brasil no comércio mundial: o efeito China e potenciais de especialização das exportações. Visões do desenvolvimento. Rio de Janeiro: BNDES, 2005.

PUGA, Fernando. Por que crescem as exportações brasileiras. Visões do desenvolvimento. Rio de Janeiro: BNDES, 2006.

RICARDO, David. Princípios de economia política e tributação. V. 1. São Paulo: Nova Cultural, 1996. 318p. 
SCHMIDT FILHO, Ricardo. Uma perspectiva schumpeteriana/estruturalista do padrão de competitividade internacional brasileiro: 1985-2007. Curitiba, 2011.

SCHMIDT FILHO, Ricardo; BITTENCOURT, Mauricio Vaz Lobo. O perfil tecnológico das exportações brasileiras: uma análise prospectiva para o período 1985-2004. Revista Economia \& Tecnologia, v. 6, n. 3, 2010.

SESSO FILHO, U. A.; RODRIGUES, R. L.; MORETTO, A. C.; BRENE, P. R. A.; LOPES, R. L. Decomposição estrutural da variação do emprego no Brasil, 1991-2003. Economia Aplicada, v. 14, p. 99-123, 2010.

SMITH, Adam. A riqueza das nações: investigação sobre a natureza e suas causas. Volume 1. São Paulo: Nova Cultural, 1996. 479p.

Marcel Timmer; Abdul A. Erumban; Reitze Gouma; Bart Los; Umed Temurshoev; Gaaitzen J. de Vries; I-aki Arto; Valeria Andreoni AurŽlien Genty; Frederik Neuwahl; JosŽ M. Rueda; Cantuche, Joseph. The world input-output database (WIOD): contents, sources and methods. Institute for International and Development Economics, 2012.

WIOD. World Input-output Database. Acesso em 20/05/2017. Disponível em $<\mathrm{http}: / /$ www.wiod.org $>$

WOOD, Adrian. How trade hurt unskilled workers. The Journal of Economic Perspectives, v. 9 , n. 3, p. $57-80,1995$.

WOOD, Adrian. Openness and wage inequality in developing countries: the Latin American challenge to East Asian conventional wisdom. The World Bank Economic Review, v. 11, n. 1, p. 33-57, 1997.

\section{NOTAS DE AUTOR}

\section{CONTRIBUIÇÃO DE AUTORIA}

Willian Fabricio Arboleya Lopes - Concepção; coleta e análise de dados, elaboração do manuscrito, revisão e aprovação da versão final do trabalho.

Umberto Antonio Sesso Filho - Concepção e elaboração do manuscrito. Coleta de dados Participação ativa da discussão dos resultados; Revisão e aprovação da versão final do trabalho.

Emerson Guzzi Zuan Esteves - Concepção e elaboração do manuscrito. Coleta de dados Participação ativa da discussão dos resultados; Revisão e aprovação da versão final do trabalho.

\section{FINANCIAMENTO}

Não se aplica.

\section{CONSENTIMENTO DE USO DE IMAGEM}

Não se aplica.

\section{APROVAÇÃO DE COMITÊ DE ÉTICA EM PESQUISA}

Não se aplica.

CONFLITO DE INTERESSES

Não há conflitos de interesses dos autores

\section{LICENÇA DE USO}

Este artigo está licenciado sob a Licença Creative Commons CC-BY. Com essa licença você pode compartilhar, adaptar, criar para qualquer fim, desde que atribua a autoria da obra.

\section{HISTÓRICO}

Recebido em: 09-10-2018

Aprovado em: 21-05-2020 